\title{
The role of the reactor size for an investment in the nuclear sector: an evaluation of not-financial parameters
}

Giorgio Locatelli ${ }^{1}$

Politecnico di Milano

Dept. Management, Economics and Industrial Engineering

Via Lambruschini 4/b. 20156 Milano - Italy

Tel: +39 02.2399.4096

Fax: +39 0223994083 giorgio.locatelli@polimi.it

\section{Mauro Mancini}

Politecnico di Milano

Dept. Management, Economics and Industrial Engineering

Via Lambruschini 4/b. 20156 Milano - Italy Tel: +39 02.2399.4057 Fax: +39 0223994083 mauro.mancini@polimi.it

\section{Please quote this paper as:}

G. Locatelli, M. Mancini "The role of the reactor size for an investment in the nuclear sector: an evaluation of not-financial parameters". Progress in Nuclear Energy. Volume 53, Issue 2, 2011, Pages 212-222 


\section{ABSTRACT}

The literature presents many studies about the economics of new Nuclear Power Plants (NPPs). Such studies are based on Discounted Cash Flows (DCF) methods encompassing the accounts related to Construction, Operation \& Maintenance, Fuel and Decommissioning. However the investment evaluation of a nuclear reactor should also include not-financial factors such as siting and grid constraints, impact on the national industrial system, etc...

The Integrated model for the Competitiveness Assessment of SMRs (INCAS), developed by Politecnico di Milano cooperating with the IAEA, is designed to analyze the choice of the better Nuclear Power Plant size as a multidimensional problem. In particular the INCAS's module "External Factors" evaluates the impact of the factors that are not considered in the traditional DCF methods.

This paper presents a list of these factors, providing, for each one, the rationale and the quantification procedure; then each factor is quantified for the Italian case. The IRIS reactor has been chosen as SMR representative.

The approach and the framework of the model can be applied to world wide countries while the specific results apply to most of the European countries. The results show that SMRs have better performances than LRs with respect to the external factors, in general and in the Italian scenario in particular.

\section{KEYWORDS:}

Not-financial evaluation, SMR, Competitiveness, Risk, Siting, Industrial development 


\section{Introduction}

The IAEA defines as "small" those reactors having the electrical output lower than 300 MWe and as "medium" those reactors having the electrical output between 300 and 700 MWe (IAEA, 2006). SMRs were developed during the '50s and the '60s: then, in order to exploit the "economy of scale", the design was scaled to $1 \mathrm{GW}$ and more. Nowadays there is a renewed interest toward SMRs with innovative solutions in their design. Ingersoll (INGERSOLL, D.T., 2009) calls these reactors "Deliberately Small Reactors", because the small/medium size is essential to develop the features able to give them the benefits in safety, operational flexibilities and economics. From now on, we consider as SMR the Light Water Reactors (LWR) having the innovative features presented in the Ingersoll's paper.

The Politecnico di Milano university, collaborating with the IAEA, is developing a model, called INCAS (Integrated model for the Competitiveness Assessment of SMRs), to assess the advantages and the disadvantages of SMRs with respect to LRs. INCAS compares the choice of investment in SMRs or LRs considering the same overall power (i.e. few LRs respect to many SMRs) and providing monetary and not monetary indicators. Boarin and Ricotti (BOARIN, S., Ricotti, M.E., 2009) presenting the monetary indicators (such as Net Present Value (NPV), equity and debt analysis, cumulated cash flows profiles etc.) demonstrates the existence of scenarios where the investments in SMRs is more attractive than an investment in LRs. Not monetary factors (from now on external factors) are addressed in Mancini et al (MANCINI, M., Locatelli, G., Tammaro, S., 2009). This paper updates the previous study, with new algorithms and factors, and tests the new framework on the Italian scenario. 


\section{Method}

The goal of this paper is to provide a list of external factors and their quantification in the Italian scenario. Each factor is addressed with the following scheme:

- definition (what it is);

- explanation (why it matters);

- quantification algorithm (how to quantify);

- results regarding the Italian scenario (results in the scenario).

Comparison between LRs' and SMRs' impacts must be always addressed considering the same amount of power: a generic 1340 MWe LR will be compared to four 335 MWe units. SMRs will be evaluated both in the same site and spread on four different stand-alone installations. Even if most of the results are related to Italy, this framework is the starting point for the assessment in a generic country, because includes also factors not differential for Italy (but potentially differential for other countries). Moreover, the algorithms can be applied almost everywhere. Concerning most of the external factors, the Italian case is quite similar to many OECD countries: the main difference is that there are not NPP producing electricity for commercial purpose.

The factors analyzed in the paper are: Spinning Reserves Management, Electric Grid Vulnerability, Public Acceptance, Technical Siting Constraints, Risks Associated to the Project, Impact on National Industrial System, Time-to-market, Competences Required for the Operations, Impact on Employment, Incremental Design Robustness and Historical and Political Aspects. 


\section{Spinning Reserves Management}

Ancillary services ${ }^{2}$ are in charge to maintain the security and the quality of electricity supply (REBOURS, Y., Kirschen, D., 2005). To control the system frequency is the most important of them: it requires that a certain amount of active power be kept in reserves, to re-establish the balance between load and generation in continuous. Such reserves are usually named as “spinning reserves", but his definition varies among countries according to (BERIZZI, A., Bovo, C., Benini, M., Migliavacca, G., 2005), (REBOURS, Y., Kirschen, D., 2005), (KIRBY, B.J., 2003):

- $\quad$ time to be fully available to serve loads;

- $\quad$ sources of power: synchronized or un-synchronized power stations, responsive loads, etc;

- $\quad$ automatic supply or under signal of the Transmission System Operator (TSO).

For our purpose, we define spinning reserves as the unutilized generation capacity which can be activated by the TSO to control the electric system frequency, independently from the time window of availability.

Figure 1 is a schematic representation of what happens because of an outage of a generation unit. Consider six units serving six isolated load areas: when unit \#6 turns-off, the $6^{\text {th }}$ area demand should be satisfied by the other active units. After the first frequency drop, units serving areas from 1 to 5 will increase their output under signal from TSO. (Hp.: grid connections have sufficient transport capacity to accept additional load. Grid constraints will be evaluated in other factors).

\footnotetext{
${ }^{2}$ Functions performed by electrical generating, transmission, system-control, and distribution system equipment and people to support the basic services of generating capacity, energy supply, and power delivery
} 


\section{[FIGURE 1 HERE]}

\section{Figure 1 - Providing for the outage of a generating unit}

Spinning reserves could be a differential factor because the smaller is the size of lost unit, the smaller is the necessary reserves, however this link is not so direct. Supply of the spinning reserves is a TSO's responsibility: it buys forecasted bands of generation capacity from utilities through mechanisms, markets and prices which are always country-dependent. In every case, spinning reserves are a cost for the TSO and so, indirectly, for the final user. TSO must manage a trade-off between the willingness to guarantee security of supply and the need to contain costs. There are two main kinds of methods to determine spinning reserves (GALIANA, F.D., Bouffard, F., Arroyo, J.M., Restrepo, J.F., 2005):

1. Security methods. Simple deterministic methods: their first objective is to maintain security and quality of supply. The amount of reserves must cover the worst power station outages (O'SULliVAN, J.W., O'Malley, M.J., 1999), (ORTEGA-VASQUEZ, M.A., Kirschen, D.S., Pudijianto, D., 2006), which from now on will be named Largest Contingency (LC).

2. Optimising methods. The trade-off between cost and service is optimised by probabilistic methods, linear programming, cost-benefit analysis and unit commitment programs, (GALIANA, F.D., Bouffard, F., Arroyo, J.M., Restrepo, J.F., 2005), (ORTEGA-VASQUEZ, M.A., Kirschen, D.S., Pudijianto, D., 2006), (GOOI, H.B., Mendes, D.P., Bell, K.R.W., Kirschen, D.S., 1999), (RUIZ, P.A., Sauer, P.W., 2008), (STREIFFERT, D., 1995). They 
require the estimation of the probability and amount of load shedding for different system conditions, which represents a possible difficulty (MOYA, O.E., 2005).

To establish a new NPP could require a boost in the spinning reserves. The following procedure quantifies the impact of reactor size on the required reserves under two assumptions:

- total amount of reserves is equal to the foreseen LC (security method);

- $\quad$ price of reserves is always fixed by market. The procedure assumes a medium constant price: the smaller LC is, the smaller required reserves are and the lower the bills will be.

The main steps are:

1. Split electric system in different areas which can be considered like isolated systems (O'SULLIVAN, J.W., O'Malley, M.J., 1999): we assume that only units of the same area can supply active power.

2. Calculate the LC for every area: it is the sum of the two largest generating units. The Worst Event (WE) is the contemporary outage of the two main autonomous groups of generation in the area.

3. Hypothesize to establish in each area a $1340 \mathrm{MWe}$ LR or four stand-alone $335 \mathrm{MWe}$ SMR. Calculate new LC for each of new cases and the difference from the actual LC. If difference is not zero, new NPPs increase required spinning reserves and the burden for TSO.

4. Sum the differences of all areas for each configuration: one LR and four SMRs. Results measure the increase of reserves due to LRs or SMRs construction on the whole territory. The nearer to one the ratio between sums is, the smaller the differential impact will be. 
Impact of spinning reserves is country-dependent and has the potential to strongly promote the SMR choice. It depends on the established generating units and on their geographic distribution

\section{Italian scenario}

TERNA, the Italian TSO, buys spinning reserves and other ancillary services in the Market for Dispatching Services (MSD). In MSD, utilities offer their willingness to vary their output for a certain amount, in response of signals from TSO; TSO buys this right (BERIZZI, A., Bovo, C., Benini, M., Migliavacca, G., 2005). The ancillary services are specified in (TERNA, 2004): there are three different kinds of reserves but only secondary and tertiary reserves compose spinning reserves as previously defined. Primary reserve is activated automatically and TSO does not pay for it, because (TERNA, 2004) provides that every generating unit must guarantee a $\pm 1,5 \%$ band of capacity for the continuous balance of the system. So, it is not differential for our purpose. In case of outages, primary reserve is exploited automatically after the immediate fall of frequency. It must be restored as soon as possible by secondary and, next, tertiary reserves that TERNA bought on forecast base.

Assuming that total amount acquired by TERNA derives from LC evaluations, we apply the algorithm to the Italian case. Italian electric system was split in the same eight areas used by National Control Centre of TERNA. They can be considered as isolated systems because interconnections between them are the most congested (TERNA, 2008), (TERNA, 2009). The largest Italian generating units for LCs owned by Italian utilities are in Table 1. 


\begin{tabular}{|c|c|c|c|c|c|c|c|c|}
\hline \multirow{2}{*}{ AREA } & \multirow{2}{*}{ ACTUAL } & \multirow{2}{*}{ ACTUAL } & \multicolumn{3}{|c|}{1 LR } & \multicolumn{2}{|c|}{ 4 x 1 SMR } \\
\cline { 5 - 9 } & WE & LC & WE & LC & DIFF. & WE & LC & DIFF. \\
\hline Torino & $790+800$ & 1.590 & $1.340+800$ & 2.140 & 550 & As actual & 1.590 & 0 \\
\hline Milano & $800+850$ & 1.650 & $1.340+850$ & 2.190 & 540 & As actual & 1.650 & 0 \\
\hline Venezia & $660+660$ & 1.320 & $1.340+660$ & 2.000 & 680 & As actual & 1.320 & 0 \\
\hline Firenze & $390+390$ & 780 & $1.340+390$ & 1.730 & 950 & As actual & 780 & 0 \\
\hline Roma & $770+660$ & 1.430 & $1.340+770$ & 2.110 & 680 & As actual & 1.430 & 0 \\
\hline Napoli & $660+660$ & 1.320 & $1.340+660$ & 2.000 & 680 & As actual & 1.320 & 0 \\
\hline Palermo & $376+376$ & 752 & $1.340+376$ & 1.716 & 964 & As actual & 752 & 0 \\
\hline Cagliari & $575+350$ & 925 & $1.340+575$ & 1.915 & 990 & As actual & 925 & 0 \\
\hline SUM & & 9.767 & & 15.801 & 6.043 & & 9.767 & 0 \\
\hline RATIO & & & & $+61,8 \%$ & & & $+0,0 \%$ & $\mathbf{0}$ \\
\hline
\end{tabular}

Table 1 - Actual and differential reserves in the Italian scenario

The construction of a LR in every area would require a 61,8\% higher reserves, while SMRs do not vary the actual situation.

The ratio between sums is equal to 0 and confirms that impact on required spinning reserves strongly promotes the SMR choice. 


\section{Electric Grid Vulnerability}

A power system can become vulnerable in case of natural calamities, power system component failure, human errors etc. The main effects of vulnerability are the large blackouts due to cascading failures of a large number of transmission lines. While in the spinning reserves factor we considered outages of the generating units, now the focus is on the failures of lines, when generators are fully available.

When a power line fails, the electric flow is shifted to the neighbouring lines, which could become overloaded. In these cases, new failures can lead to a cascading effect with consequences on the whole electric system. Cascading failures led to the blackout in August 10, 1996, for 11 different Western U.S. states, and to the largest blackout in the US's history in August 14, 2003 (CRUCITTI, P., Latora, V., Marchiori, M., 2004).

The purpose of electric grid vulnerability assessment is to provide a quantitative measure of system's ability to preserve node connectivity in case of failures. Three different kinds of methods have been proposed to assess vulnerability in literature:

1. Deterministic methods (GENESI, C., Granelli, G., Marannino, P., Montagna, M., Zanellini, F., Innorta, M., July 2007) use massive indices based on the distance of the operating points and the collapsed point, or on loss of load probability, expected power loss etc;

2. Complex Network based methods (CRUCITTI, P., Latora, V., Marchiori, M., 2004), (ARIANOS, S., Bompard, E., Carbone, A.), investigate topological structure and resilience of power grids adopting a complex network description. Global Efficiency (CRUCITTI, P., Latora, V., Marchiori, M., 2004) is a quantitative measure of the degree of a complex network ability to provide service in case of line outages: it contributes to derive the final required Vulnerability Index $(V I)$ of the power system.

3. Monte Carlo based methods use Monte Carlo simulation for probabilistic assessment. 
A quantitative way to evaluate the size's impact on electric grid vulnerability considers the VI of the country's grid. For LR/SMR comparison, the procedure in (CRUCITTI, P., Latora, V., Marchiori, M., 2004) must be applied to simulate different scenarios:

1. first LRs and then SMRs must be substituted in the different generation nodes of the grid;

2. for every new configuration, the calculation of VIs evaluates the effect of outages of different transmission lines.

This evaluation of the impact can be understood from Figure 1. Let us consider the connections with unit \#6: if one (or more) of them fails, the whole output of generating site will flow through the remaining lines. For the same level of lines' congestion, the larger the site's output is and the higher the risk of following overloads will be. So, it is obvious that a LR increases grid vulnerability with respect to the installation of a stand-alone SMR. The differential impact is higher in the case of generation nodes connected to the most congested transmission lines.

Electric grid vulnerability has the potential to be strongly differential and to promote the SMR choice. Obviously this factor is not differential considering four SMRs in the same site.

\section{Italian scenario}

In September 28, 2003, a failure due to the sag of the electrical line in Lucomagno (Switzerland) caused a blackout for almost the entire Italy (SFORNA, M., Delfanti, M., 2006). This event demonstrated the vulnerability of Italian grid. Moreover, (TERNA, 2009) highlights highlycongested lines which are bottlenecks of the system:

- the cheaper energy available in central Europe led the northern interconnections close to the security limits, as said in (GALIANA, F.D., Bouffard, F., Arroyo, J.M., Restrepo, J.F., 2005) ; 
- the distribution of generation capacity loaded connections between Piemonte and Lombardia, and between central Italy and Northern and Southern territories.

Grid vulnerability promotes the SMR choice in the Italian scenario too, especially if new installations will be connected to previously listed connections 


\section{Public Acceptance}

Public acceptance of nuclear power is the attitude of the public towards the deployment of this technology. It is possible to evaluate an overall population's attitude and a local population's one. The two different sides of public acceptance have different impacts on the choice of size.

\subsection{Overall population's attitude}

In the nuclear field this factor is controversial. Even if the technology is intrinsically safe and there are not externalities, the public in many countries does not support nuclear energy (SCHNEIDER, M., Thomas, S., Froggatt, A., Koplow, D., 2009).

This is because, in the public's mind, a system with small probability of failure and large consequences is seen as more risky than the opposite, as the common fear of air crashes (SJOBERG, L., 1999). Fischoff's law (FISCHOFF, B., Slovic, P., Lichtenstein, S., Read, S., Combs, B., 1978) bears that level of acceptable risk is inversely related to the number of people exposed to that risk. Slovic (SLOVIC, P., Fischoff, B., Lichtenstein, S., 1980) concluded that belief about the catastrophic potential of nuclear power is the major determinant of public opposition. Other main factors influencing the attitude toward NPPs are:

- trust in government and institutions (SLOVIC, P., 1993);

- knowledge and competences on nuclear topics, which are tightly related to active nuclear power generation in the country (SLOVIC, P., Fischoff, B., Lichtenstein, S., 1980);

- timing and level of public involvement in the decision. Public accepts risks from voluntary activities roughly 1000 times greater than from involuntary activities that provide the same level of benefit (FISCHOFF, B., Slovic, P., Lichtenstein, S., Read, S., Combs, B., 1978);

- risk perception about waste management and disposal (SJOBERG, L., 2009).

Considering different sizes: 
1. public competences are not sufficient to understand safety improvements. Deliberately SMRs have a lower Core Damage Frequency (CDF) thanks to their design, but public has not an education which makes him able to appreciate a reduction of $\mathrm{CDF}$ from $10^{-7}$ to $10^{-8}$ (as in the comparison between Westinghouse's AP1000 and IRIS (CARELLI, M.D., 2003), (MATZIE, R.A., 2008));

2. public perception of a severe accident is not size-dependant because, in the people's mind, both SMRs and LRs involve the same catastrophic consequences;

3. III/III+ GEN SMRs and LRs do not produce different quantity or toxicity of waste. These issue will become differential only with the exploitation of IV GEN disruptive technologies. Considering near-term technologies, overall population's attitude is not differential.

\subsection{Local population's attitude}

Attitude of local communities toward nuclear energy could be different from the majority of country's population. The main cause is the Not-In-My-Backyard (NIMBY) syndrome: even if public does not oppose building of new NPPs, it is possible a fierce opposition from local communities who will have to host them.

NIMBY phenomenon is probably due to the way people evaluate risks in a siting situation: perceived risks become the overriding factor and the weighting given to a potential benefit is greatly reduced (TANAKA, Y., 2004). Educational system, experience in infrastructure project management and culture-specific features vary the syndrome's intensity.

Where NIMBY is strong, to find four different sites for SMRs is more difficult than a single LR site, because to solve local oppositions requires a great effort in terms of "diseconomy of hassle" (INGERSOLL, D.T., 2009), money and risk augmentation. 
In this case, public acceptance is differential and promotes few large power sites. So, to consider four SMRs in the same site makes public acceptance not differential, even in the case of strong NIMBY syndrome. Conversely, to spread four SMRs in four sites can be challenging.

\section{Italian scenario}

The lack of public nuclear knowledge is specific of the Italian case because of 20 years of "silence": 76\% (SOCIETÀ, ARIS Agenzia di Ricerche Informazione e, 2008), (FOUNDATION, EnergyLab, 2008), (LOZZA, E., Mazzoletti, G., 2008) of Italian people state low or null knowledge on this topic. Polls show that 53\% of the Italian population support nuclear renaissance, but only 30-40\% (DEMOS, 2008) would be ready to host an NPP near his town. The phenomenon of local opposition is increasing constantly (SOCIETÀ, ARIS Agenzia di Ricerche Informazione e, 2008). Nowadays, Italian infrastructures which are facing local opposition are 264: 45 of them are contested since 2004, without showing improvements of public acceptance.

The Decide-Announce-Defend approach (KUHNREUTHER, H., Linnerooth-Bayer, J., Fitzgerald, K., 1996) used by Italian government has reinforced NIMBY phenomenon. So, in the Italian case, to quadruple sites is strongly less convenient than the single site alternative. 


\section{Technical Siting Constraints}

Besides NIMBY, already addressed in section 5, there are technical constraints that a site must satisfy.

The most important constraints in the choice of NPP site (KUHNREUTHER, H., LinneroothBayer, J., Fitzgerald, K., 1996), (MACINTOSH, A., 2007) can be clustered in two classes.

\subsection{Constraints differential only if a single unit is compared to four stand-alone SMRs (in four sites)}

Water usage. A smaller sized plant produces less power: it results in a smaller water demand (INGERSOLL, D.T., 2009). So, low flow-rate rivers can be used as sources of cool water: it could be the simplest and cheapest solution in warmer climates too, instead of exploiting the technologic-advanced expensive solutions required for LRs.

Grid connections. A site for a LR must have a grid connection able to receive a huge amount of power. On the opposite, a stand-alone SMR can fit where is not feasible an extension of the current electric grid or the extension is very expensive. Benefits from SMR choice were quantified in the Italian case through a methodology valid worldwide in (MANCINI, M., Locatelli, G., Tammaro, S., 2009).

Population density. Advanced SMRs present improvements in overall defence-in-depth (IAEA, 2008), that will enable a reduction in the EPZ requirements. However, since no one regulatory system has modified EPZ requirements until now and supposing the same scenario for the future , this sub-factor reduces SMRs' flexibility because they need four different sites.

Others. Some sub-factors impede installation of both LRs and SMRs in a certain area, but they are differential anyway. In countries where these features are common, it is more difficult to find four different areas available for stand-alone SMRs. This group includes:

- volcanic or tsunami dangers; 
- risks of extreme whether events as cyclones or floods;

- ecological, heritage or tourist areas etc.;

\subsection{Constraints differential in every configuration}

Seismic robustness. The smaller size of SMRs' nuclear island facilitates the use of seismic isolators similar to those used for conventional buildings (INGERSOLL, D.T., 2009). They permit to standardize NPP seismic protection: it is less expensive if compared to the site-specific requirements of LRs.

Transport infrastructure. In some instances large vessels and modules used in LRs limit the siting of new plant to coastal areas or along major rivers. In contrast, many SMRs' components can be transported by smaller river barges, rail or trucks: smaller components allow a higher flexibility in siting for SMRs.

Technical siting constraints are country-specific differential. Every sub-factor has different importance in each country: the objective is to understand if relevant issues for the country give more flexibility to the siting of SMRs or not.

Italian scenario

SMRs fit better Italian electricity grid (MANCINI, M., Locatelli, G., Tammaro, S., 2009) and his spread seismologic activity. Large modules and higher needs of cool water push the siting of LRs to coastal areas, because of the lack of Italian high flow river.

As said in (REBOURS, Y., Kirschen, D., 2005) Italian NIMBY strongly reduces the possibilities for stand-alone SMRs. Besides, the great diffusion of heritage and tourist areas amplifies syndrome's effects.

Beyond NIMBY, technical siting constraints make the siting of SMRs more flexible in the Italian scenario. 


\section{Risks Associated to the Project}

This factor deals with the risks in the delivery of a NPP. We took a complete list of risks from (ASSOCIATION, World Nuclear, 2008) and consolidated it with issues in (INGERSOLL, D.T., 2009), (ENERGY, U.S. Department of, 2005). We identified three classes of risks: FOAK (FirstOf- A-Kind), supply chain and construction risks.

\subsection{FOAK risks}

They are risks with the same probability of occurrence for both SMRs and LRs, but they have differential magnitude in the two cases. In fact, these risks impact on the capital employed in the single FOAK: it is smaller for SMRs, therefore size does not reduce probability, but reduces the impact of risks. The major FOAK risks are:

- Authority activities on FOAK. FOAK bears more uncertainties on safety issues, therefore activities from safety agencies are more likely. AREVA EPRs suffered authority activities even if they has been under construction for five years (HSE, STUK, HSN, 2009): it demonstrates the level of uncertainties on FOAK units.

- NIMBY. Opposition of local communities can increase the difficulty in the licensing and construction of FOAK in the site. UK approach is the best practice to mitigate this risk: the first step is to identify the sites and to gain local support, and only after the government announces an International bid.

- Political risk. Nuclear projects cannot proceed without government support. Changes in driving forces can obstacle new NPP investments if beliefs of these forces on nuclear energy are different.

All the three classes have the same probability to impact on SMRs or LRs, but capital on which they impact is always lower in the SMR case. 


\subsection{Supply chain risks}

They include all the uncertainties on having the right resources (components, modules and equipments) on the right place at the right time. The exploitation of pre-fabrication, modularisation and standardization in SMRs' design can further control these risks (FORUM, U.S. DOE Nuclear Energy Research Advisory Committee and Generation IV Interational, 2002). The specific construction approach is technology-dependent, but through a smaller size:

- the physically smaller and simpler components provide the increase of the number of fabrication options (INGERSOLL, D.T., 2009), (IAEA, 2001). For example, LRs require large forgings which can be provided by only one supplier worldwide (Japan Steel Works) (INGERSOLL, D.T., 2009), (SCHNEIDER, M., Thomas, S., Froggatt, A., Koplow, D., 2009), (ASSOCIATION, World Nuclear, 2009). This will be a source of relevant delays in the case of many contemporary new orders;

- SMRs' components and modules can be produced by a greater number of suppliers in the world, reducing worldwide backlog. Detailed engineering of GEN III/III+ SMRs is not complete: of course, a higher number of suppliers will be available only when the production process of every component will be known;

- modularized elements of SMRs were designed to be transported in an easier way: SMRs have a higher percentage of modules transportable by trucks or rail, even if the precise configuration is technology-dependent. So, the supply chain is less vulnerable to delays, especially in case of interrelated deliveries.

\subsection{Construction phase risks}

A considerable vulnerability of large plant construction is the amount of work that must be performed on site[2]. The SMRs' higher percentage of components fabricated in factory implies: 
- improvement of on-site personnel safety, because they handle fewer modules;

- simpler assembly operations, thanks to standardization and a module-oriented design;

- lower drop-off in field installation effectiveness when the design is reproduced at another site by a different construction team. A factory standard set of assemblies reduces the construction time variability (WALLACE, E., Matzie, R., Heiderd, R., Maddalena, J., 2006);

- special equipments, as Very Heavy Lift cranes for installation, or large barges for transport, are not required for some SMR designs. Even if they were necessary, their purchase can be justified by the higher number of SMR units. In both instances, it is possible to avoid delays related to scarce co-ordination between equipment rents and previous scheduled activities.

\section{Every class of risk promotes the SMR choice.}

\section{Italian scenario}

Debate on the Italian nuclear comeback is very recent: every source of uncertainty is important in this phase. The Decide-Announce-Defend approach of the beginning is the opposite of the UK strategy to obtain public support. Besides, the two opposite political forces still have different beliefs on nuclear energy and a safety authority has not yet been appointed.

Uncertainties afflicting the Italian case amplified SMR's benefits for the mitigation of every class of risks.

In the Italian case, high risks associated to the nuclear projects promote the SMR choice, thanks to the lower capital they put on risk. 


\section{Impact on National Industrial System}

This factor is important especially for a public investor: the higher is the percentage of manufacturing and construction work content assignable to national industries, the higher the positive effect on GDP of the country will be.

There has been no real growth in the nuclear industry for many years and the consequence is the current shortfall in qualified suppliers of nuclear equipments and components (ENERGY, U.S. Department of, 2001), (ASSOCIATION, Nuclear Industry, 2008).

New suppliers of nuclear renaissance need:

- a nuclear-grade qualification as ASME N-Stamp;

- manufacturing system adjustments: the shortfall of suppliers is also related to bottlenecks in manufacturing capacity (SCHNEIDER, M., Thomas, S., Froggatt, A., Koplow, D., 2009).

Considering the comparison between LRs and SMRs, the steps for the ASME N-Stamp certification are not size-dependent. The main limit for national industries to become suppliers of new NPPs is related to the capacity of their production systems.

The two main drivers that define the technical feasibility of NPPs' components are dimension and complexity: the higher they are and the higher investments for machinery and know-how will be. Figure 2 presents GEN III+ LR's and SMR's value breakdown obtained from expert elicitation. However, every design has its own features and would require specific considerations: for example, IRIS's integral layout implies the fabrication of a forged vessel which can be included among large dimension components. Main purpose of the approach is to depict the potential differential impact of "average" large and small-medium designs from a qualitative point of view. 
Evolutionary components are parts which fabrication process is known: for the revolutionary components, instead, vendors know expected features but there is still need for research on materials and fabrication process required to obtain them. The components in the highlight areas require lower investment in machinery and know-how acquisition:

- Ingersoll (INGERSOLL, D.T., 2009) states that the physically smaller components provide for a large number of fabrication options and generally can be built using more conventional fabrication capabilities that already exist domestically. The case of NuScale design is a perfect example of this statement: the reactor modules can be entirely fabricated at existing local U.S. manufacturing facilities;

- if component design is standard and well-known, its development and fabrication will be cheaper and will require lighter development of new competences.

\section{[FIGURE 2 HERE]}

\section{Figure 2 - LRs' and SMRs' value breakdown}

SMR concentrates in the highlight areas (that we can consider as "not critical") a value 20-30\% superior than LR, therefore the value in critical areas for SMR is $10 \%$ instead of $40 \%$ as for LR. The final considerations are:

1. SMRs require a less capital intensive investment for the development of know-how and manufacturing systems required to become a nuclear-grade supplier. Effort to buy large capacity machinery and to find competences (for example training of a large forgings master took about 10 years) required by LR can make the investment for a new comer prohibitive; 
2. the equipment cost for four SMRs is about $20 \%$ higher than for LR because of the economy of scale (CARELLI, M.D., Garrone, P., Locatelli, G., Mancini, M., Mycoff, M., Trucco, P., Ricotti, M.E., 2009). The difference is a burden for investors but the other side of the coin is that it contributes to the economic justification of suppliers' investments.

So, SMRs have the potential to develop a wider supply chain with a higher number of suppliers inside national burdens. Investment to become a SMR supplier is more competitive. Difference with LR investment is heavier for industries of countries with low participation in nuclear supply chain.

In general, impact on national industrial system is differential and promotes the SMR choice.

\section{Italian scenario}

U.K. Nuclear Industry Association (ASSOCIATION, Nuclear Industry, 2008) states that national industries will be able to supply about the $80 \%$ of total value of new expected LRs. The difference with the achievable percentage by SMR choice is low for a country that maintained his industrial infrastructure, also because currently it operates NPPs.

Italian industries instead have kept only a little participation in the nuclear supply chain. To face a new nuclear program, Italian industrial system needs higher number of N-Stamp qualified firms, new manufacturing capacity and to recover best manufacturing practices.

SMR choice can increase the involvement of Italian firms in the new nuclear program. Through expert elicitation it was estimated that $50-60 \%$ of SMRs' value could be supplied by Italian industries, against the $40 \%$ of a LR. 


\section{Time-to-market}

Time to market is the time required to license and build planned NPPs, and so to sell the first MWh to the electric system. It limits the opportunities created by the broad-scale deregulation of many electricity markets in the world (ENERGY, U.S. Department of, 2001).

Licensing time. Since all the SMRs in the same site are identical, it is oblivious that the same steps in the licensing process, after the first unit, become redundant. Licensing time for a SMR NOAK (Nth-Of- A-Kind), in a certain site, will be shorter than a LR (MANCINI, M., Locatelli, G., Tammaro, S., 2009). On the contrary, it is equal considering the FOAK unit of SMRs and LRs. Since the first MWh will be sold after the delivery of the FOAK, the licensing time is not a differential part of LRs' and SMRs' time-to-market.

Construction time. The differential part of time-to-market is the construction timeframe: it includes the pre-construction and site preparation activities, plant construction (from first concrete to fuel load), fuel load and pre-operational testing.

Site preparation and procurement for a LR take 1.5 years, while field installation and preoperational tests take 3.5 years: the total construction time for a LR is five years, considering the most common design installed worldwide (ENERGY, U.S. Department of, 2005), (ASSOCIATION, World Nuclear, 2009), (ASSOCIATION, Nuclear Industry, 2008) (ECONOMICS, Oxford, 2008), (LABORATORY, Idaho National Engineering and Environmental, 2004). On the other side, construction of a Deliberately SMR takes three years (FORUM, U.S. DOE Nuclear Energy Research Advisory Committee and Generation IV Interational, 2002), (ASSOCIATION, World Nuclear, 2009), (ENERGY, U.S. Department of, 2001). So SMRs predate the sale of the first MWh of two years.

\section{Time-to-market is differential and promotes the SMR choice.}

Italian scenario 
Time-to-market of new plants is especially important in the Italian case. Italian electricity price has been higher than European countries for the last decade: in 2007 it was the 80\% higher. Part of the gap depends on the imbalanced mix of Italian sources, which is too related to fossil fuels prices volatility. The other part is related to "the immaturity of electricity market" which involves a "silent collusion" between main Italian utilities, as experts and authorities bear (ELETTRICO, Gestore del Mercato, 2007), (GAS, Autorità per l'energia elettrica ed il, 2009), (CORBELLINI, F., November 26, 2008), (PROSPERETTI, L., 2008). This collusion reduces price benefits deriving from a deregulated market.

1. Italian generation is lower than national demand, so utilities must buy the gap of request from French and Swiss plants. Even if these contributes are needed only during demand peaks, agreements provide for a continuous import from foreign nuclear plant, because they exist mainly for satisfying Italian needs. Continuous import saturates interconnections of the Italian grid with Europe (CORBELLINI, F., November 26, 2008): so Italy is not really interconnected to the European market, where prices are lower. Italian utilities slowed down the construction of new interconnections in the past, trying to maintain this situation as long as possible (PROSPERETTI, L., 2008): for this reason, Italian Authority sanctioned the separation of property between generation and transmission systems.

2. Virtual isolation from cheaper sources facilitates collusive behaviours. Italy adopted the Marginal Price System, in which the electricity price depends on the last plant "called to generation": such process brings a unique price that the dominant utility can drive to be equal to the production cost of its less efficient plant. This cost is higher than other utilities' plants 
too: silent collusion rises from here (GAS, Autorità per l'energia elettrica ed il, 2005),

(PROSPERETTI, L., 2008).

By reducing the gap between the Italian generation and demand, it will be possible to free the saturated grid interconnections with other European countries. Once happens that so different prices will be really connected, deregulated market mechanisms will be able to reduce Italian electricity price. The two-years lower SMR's time-to-market would accelerate this process.

\section{In the Italian case time-to-market strongly promotes the SMR choice.}

\section{Competences Required for the Operations}

In next years, the world will face a shortage of people with high level of knowledge and skills in the nuclear field. Nuclear education and training have been decreasing for several years with declining of university enrolment, dilution of university course content and high retirement expectation (SCHNEIDER, M., Thomas, S., Froggatt, A., Koplow, D., 2009), (ENERGY, U.S. Department of, 2001), (OECD/NEA, 2000), (OECD/NEA, 2004).

In the classical six-roles nuclear operations team (O'CONNOR, P., O'Dea, A., Flin, R., Belton, S., 2008), we can identify two kinds of operators according to their skills: high-level operators for the central control room (CCR), and medium-level operators for routine checks under the direction of the CCR team. High-level operators are the bottleneck from the competences point of view: their training could be difficult, especially for a country which begins a new nuclear program. The worldwide shortage makes spill-over from other countries more complicated: in France too, in spite of the embedded nuclear culture, the demand of nuclear experts has tripled in last decade (SCHNEIDER, M., Thomas, S., Froggatt, A., Koplow, D., 2009).

Constraints for high-levels operators training are not time or cost: cost is a negligible percentage in the life cycle and the eight-years conservative period for licensing and construction is 
sufficient to train an engineer. The real constraint is the education system of the country: it must give a sufficient background of engineers' competences and a following nuclear-grade education, so that training could be able to develop high-level operators. The major drivers to define education system's level (OECD/NEA, 2000), (OECD/NEA, 2004) are:

- established nuclear power: it means better job expectations and better public opinion;

- existence of specific nuclear engineering degree courses: date of creation, number of graduates in every year, trend in the number of enrolments, collaboration with Nuclear Steam Supply System (NSSS) Vendors;

- position of the country's scientific and technical schools in International rankings;

- international collaborations of local universities and nuclear industry: mobility of researchers and experts, mechanisms for sharing best practices in promoting nuclear courses, agencies who promote and co-ordinate these collaborations;

- nuclear Research \& Development: publicly funded and privately funded researches, number of active research reactors.

Deliberately SMRs can be the key feature for countries with low nuclear-grade-training capabilities, because "the qualification and training requirements for staff of the new SMRs have the potential to be lower than those required by the current reactors, however training of staff should be to the level demanded by the design and operating requirement of the SMRs" (IAEA, 2001). The new SMR systems have incorporated features to make them simpler and quicker to build, operate, inspect, maintain and repair: 
- standardization will reduce requirements for plant staffing: the reduced variety of components and modules results in lower variety of testing and maintenance activities, knowledge and training requirements;

- the lower number of systems and components can result in a direct reduction of the number of inspection, testing and maintenance activities.

Even if literature supports that SMRs require a lower average degree of nuclear competences, utilities, agencies and government will require some high-level operators to carry out the main tasks in new NPPs. Therefore, SMRs will require competences till the same high level of LRs, as in figure 3.

So if:

1. range of competences is equal;

2. number of operators of SMRs are higher than LRs;

3. medium staffing requirements for SMRs are lower (IAEA, 2001);

the conclusion is that SMRs require a lower percentage of high-level operators than LRs do (Figure 3).

\section{[FIGURE 3 HERE]}

Figure 3 - Requirements for operators' skills

\section{Competences for the operations are a differential critical factor for countries with a poor technical education system.}


Competences are not differential for countries where education system gives an average highlevel of basic technical knowledge, so that the successive training will be able to form high-level operators. If competences owned by graduates are poor, training programs can not create highlevel operators.

\section{Italian scenario}

Italy has suffered the lack of NPPs for 20 years but has been able to maintain core skills and competences:

1. there are six nuclear engineering master degree courses and other less specific university courses. Many of these involve participation to International projects and with worldwide NSSS Vendors;

2. there are two reactors for research;

3. Enel, the biggest Italian utility, is involved in foreign nuclear projects:

- it is constructing two 440 MWe reactors in Mochovne (Slovakia);

- operates the nuclear power plant in Cernavoda (Romania);

- owns $12,5 \%$ of the capital employed in Flamanville project and sent 60 Italian engineers for training in the new Europen Pressurized Reactor (EPR) site.

Enel estimated that commercial operations of the first NPP will start in 2020, while the last of four foreseen EPR will start in 2025. Considering that the whole 13 GWe Italian nuclear program will be covered in the 2020-2025 timeframe, the Italian system will have to educate 200 nuclear engineers every year, in opposition to the actual 80 .

\section{Competences might be slightly differential in the Italian case.}


Education system and utilities' programs are able to create high-level nuclear operators. The 10years time window permits to achieve the number of experts required, through adequate campaigns of university promotion. So, Italy has the potential to satisfy the need of competences for the operations of both LRs and SMRs. 


\section{Impact on Employment}

This aspect is important especially for a public investor because welfare of the country is an important objective of his mission. However, a private investor will be interested to the government's support following a higher number of new jobs created. This issue is so relevant that the literature is rich of frameworks for the evaluation of new jobs created from new NPP programs (ENERGY, U.S. Department of, 2005), (ECONOMICS, Oxford, 2008), (LABORATORY, Idaho National Engineering and Environmental, 2004), (KENLEY, C.R., Klinger, R.D., Plowman, C.M., Soto, R., Turk, R.J., Baker, R.L., Close, S.A., McDonnel, V.L., Paul, S.W., Rabideau, L.R., 2009), (DOMINION ENERGY INC., Bechtel Power Corporation, TLG Inc., MPR Associates, 2004). The following considerations summarise their contribution with respect to the construction and the operation phases.

\subsection{Construction phase}

There are three different impacts on employment:

1. Direct. People employed in the manufacturing of components and modules, on-site construction and operation of NPP.

2. Indirect. Jobs created in the extended nuclear supply chain: suppliers of equipment manufacturers, suppliers of machineries and building materials, agencies for inspection and safety controls.

3. Induced. Jobs created in non-nuclear industries due to the new jobs added in the previous categories. They are the sum of non-nuclear jobs that would be created because of industry growth, such as additional grocery store employees, school teachers and residential construction workers. These jobs have a significant impact especially in local economies, as 
reported in (BEZDEK, R.H., Wendling, R.M., 2006), (INSTITUTE, Nuclear Energy, 2006), (INSTITUTE, Nuclear Energy, 2004).

The differential impact on new jobs creation is evaluated considering the comparison between a LR and four SMRs in the same site.

Oxford's study (ECONOMICS, Oxford, 2008) used Input-Output analysis to define the relationships between different kinds of impact through the use of multipliers, as in Figure 4. We extrapolated direct on-site and off-site man years required for the construction of a $1340 \mathrm{MWe}$ reactor from (ENERGY, U.S. Department of, 2005), (ECONOMICS, Oxford, 2008). For what concern SMRs, the values of the two direct impacts were obtained from LRs' values through the application of labour and equipment coefficients in (CARELLI, M.D., Garrone, P., Locatelli, G., Mancini, M., Mycoff, M., Trucco, P., Ricotti, M.E., 2009). Indirect and induced impacts were obtained from the applications of multipliers.

\section{[FIGURE 4 HERE]}

\section{Figure 4 - Impact on employment during the construction phase (man years) Impact on construction employment is strongly differential and promotes the SMR choice}

1. The SMRs in co-siting configuration create $11 \%$ more man years content than LRs. Major part of new jobs opportunities created by SMRs are related to the major percentage of work content transferred off-site, through modularization and pre-fabrication approaches. Multipliers indicate that off-site direct employment drives greater indirect and induced 
effects than on-site direct employment. So, SMRs create a more beneficial impact thanks to the higher work content of facilities and the following induced effects. Moreover, this welfare benefit does not undermine attractiveness of the investment.

2. The amount of on-site employment is in Figure 5. The phased demand for LR is from (ECONOMICS, Oxford, 2008). We re-arranged the approach to three-years-construction SMRs to obtain a plausible schedule.

\section{[FIGURE 5 HERE]}

\section{Figure 5 - Phased demand for on-site employment (man years)}

The literature (SCHNEIDER, M., Thomas, S., Froggatt, A., Koplow, D., 2009) shows that one of the biggest challenges is finding qualified people, including craft labourers and technicians (qualified boilermakers, pipefitters, electricians, ironworkers), to support construction. SMRs' demand is more time-levelled, therefore it will be easier to face the shortage of qualified construction workers, even if the total number of man years is higher than LR.

\subsection{Operation phase}

Positions in this phase include permanent plant operators and engineers, managers, accountants and general staffs. Extrapolation from existing plants' experience (IAEA, 2001) shows average staffing levels of approximately one person per MW(e) for a single unit LR. For SMRs, the specific staffing level tends to increase to about 1.5 person/MWe.

But existing SMRs are only scale models of LR designs. New GEN III+ SMRs incorporate features that require fewer personnel to operate and maintain the plant in a safe and reliable 
manner. Model presented in (CARELLI, M.D., Garrone, P., Locatelli, G., Mancini, M., Mycoff, M., Trucco, P., Ricotti, M.E., 2009) concludes that a site with four 335 MWe SMRs has an O\&M cost $24 \%$ higher than a site with one 1340 MWe LR. Labour cost is about the $70 \%$ of total O\&M costs, so operational work content will experience roughly the same increase.

Concluding:

- SMRs create a higher number of new jobs also in the operation phase;

- new operation positions still involve indirect and induced impacts: SMRs and LRs are characterized by equal multipliers (ECONOMICS, Oxford, 2008), but they amplify the higher direct operation employment of the SMR.

\section{Impact on operation employment is differential and promotes the SMR choice.}

\section{Italian scenario}

In the Italian scenario there is not a full employment of the population, even considering people with a technical education, so this impact is differential. Only in a country with a full employment this factor will not be differential. 


\section{Incremental Design Robustness}

A high level of safety is the result of a complex interaction between good design, operational safety and human performances, but design features are able to impact on all these three dimensions. By the concept of design robustness the objective is to combine and to evaluate three key strategic performance areas: reactor safety, radiation safety (public and occupational) and safeguards, according to Reactor Oversight Process (ROP) of NRC (COMMISSION, U.S. Nuclear Regulatory, 2000). From these key areas, we define Design Robustness the reactor's capability to assure the core's integrity, the core's protection and the integrity of all the other components of the nuclear island, in order to guarantee the radiation safety of personnel, population and environment in every condition. It is possible to evaluate the size impact on design robustness considering the three areas separately.

1. Reactor safety considers accidents leading to significant or unplanned releases from containment. Core Damage Frequency (CDF) and Large Early Release Frequency (LERF) are the most important indicators for this dimension.

The implementation, with an acceptable cost, of safety features as passive systems and design simplification are possible only on SMR. Such features drive the elimination of several classical event initiators and passive safety guarantees higher availability of mitigation systems. For example, safety-by-design approach of Westinghouse's IRIS permits a reduction of CDF from $5,1 \times 10^{-7}$ of a GENIII+ AP1000 to $10^{-8}$ (CARELLI, M.D., Conway, L.E., Oriani, L., Petrovic, B., Lombardi, C.V., Ricotti, M.E., Barroso, A.C.O., Collado, J.M., Cinotti, L., Todreas, N.E., Grgic, D., Moraes, M.M., Boroughs, R.D., Ninotaka, H., Ingersoll, D.T., Oriolo, F., 2004). IRIS LERF is around five orders of magnitude less than large PWRs and the other GEN III+ SMR designs have a three orders lower one (MAIOLI, A., Finnicum, D.J., Kumagai, Y., 2004). 
2. Occupational Radiation Safety refers to operators' overexposure risk. Plant workers can be exposed to a high-level radiation during the maintenance of reactor coolant pumps, pressurizers, water chambers of steam generators and during refueling. So, operators exposure is strictly related to capacity factor of reactor, as it is clear from World Association of Nuclear Operators (WANO) performance indicators (OPERATORS, World Association of Nuclear, 2009).

SMRs' simplification and compactness permit the extension of scheduled maintenance and refueling interval: IRIS had been designed to extend the need for scheduled outages to at least 48 months (CARELLI, M.D., Conway, L.E., Oriani, L., Petrovic, B., Lombardi, C.V., Ricotti, M.E., Barroso, A.C.O., Collado, J.M., Cinotti, L., Todreas, N.E., Grgic, D., Moraes, M.M., Boroughs, R.D., Ninotaka, H., Ingersoll, D.T., Oriolo, F., 2004). On the other side, there is the need of outages on four units instead of the only one LR, considering the same installed power.

Total exposure depends on number and duration of outages, on single outage exposure for operator and on number of operators involved in activities. SMRs' features must reduce the total exposure on a single unit activities to at least one quarter with respect to LRs, because SMRs not being penalized. Utility policy and practices can heavily affect the total four versus one unit comparison.

3. Public Radiation Safety considers collective radiation exposure to liquid and gaseous effluents from routine nuclear reactor operations. Size does not impact on technological solutions for the control of these releases.

4. Safeguards refer to physical protection of the facility and proliferation resistance. Charlton (CHARLTON, W.S., Le Bouf, R.F., Gariazzo, C., Ford, D.G., Beard, C., Landsberger, S., 
Whitaker, M., 2008) produces a report that can be considered the most relevant for this theme, synthesizing the parameter in a likelihood scale from 0 to 1 , where the highest is the value, the highest is the proliferation risk. For a typical PWR LR of GEN III this value is 0,07, while for a SMR case with a batch loading of the fuel the parameter becomes 0,06 . Moreover, portion of SMRs' containment can be located above the ground, as for IRIS: the cost would be prohibitive for LRs. This potential low SMRs' profile makes them an extremely difficult target for aircraft flying terrorists.

Design robustness is strictly design-specific but simplification, standardization and compactness of SMRs permit to obtain certain improvement on reactor safety and physical protection. If utilities follow best common practices during outages, occupational exposure will not penalize SMRs.

\section{Design robustness is differential and promotes the SMR choice}

Italian scenario

Previous conclusion is true in the Italian scenario too, but it will be necessary to import best foreign practices to control personnel exposure. 


\section{Historical and Political Aspects}

Beside technical and financial aspects another factor is a key driver to choose a NPP: the historical relationships among industries and between industries and national states. For instance since the French state owns both Areva (the vendor) and Electricité de France (the buyer), the French reactors will be, for sure, all EPR (or a design from Areva). This factor is fundamental even if in a country there are not vendors. Also in this case the country could host contractors with an historical collaboration with certain vendors and/or the utilities could already have a relationship in a foreign market with vendors or utilities. This kinds of collaboration are usually based on long term agreements, therefore represent a driver toward the choice of a certain reactors.

Two aspects have to be considered in order to quantify this factor:

1 - the strength of the relationship among the partners: in a certain country, different firms or utilities could have a relationship with different foreign vendors.

2 - the portfolio of vendors' products: there are vendors with only design of LRs, while others offer a portfolio made of LRs and SMRs.

Considering these aspects, a tight relationship with a vendor of LR could preclude the choice of SMRs.

\section{Italian scenario}

For what concern Italian scenario, the nowadays most important utility -ENEL - has a long term relationship with EdF (therefore Areva), with a 12.5\% equity stake on 6 nuclear plants. Contrariwise, Ansaldo Nucleare, the main Italian designer and contractor in the nuclear sector, is strongly related with Westinghouse developer of AP1000 and IRIS reactors. Other industries and utilities have relationships with these two vendors, therefore different scenarios are under consideration even if in this type of analysis the scenarious can completely and quickly change 


\section{Conclusions}

The choice of NPP 's size is a degree of freedom that in the nuclear industry can play a primary role in many markets. It is already been proved that, in certain scenario, the loss of economy of scale can be balanced by the "economies of multiples" such as standardization, learning, cost sharing, modularization etc. Besides the financial parameters, there are many other "not monetary factors" able to dramatically influence the choice of an investor toward SMRs or LRs. This paper goes through all these "external factors" providing the definitions, the methods of quantification and the evaluations with respect to the Italian scenario. The results clearly indicate that SMRs fit better, or at least as LRs, all the factors. However it is important to point out that Italian NIMBY syndrome limits the possibility of spreading SMRs in different sites, and so to exploit the advantages in grid stability and site availability. Therefore, the only plausible scenario for the Italian case is the concentration of four SMRs in each site. Respect to this configuration, the SMRs still reap many advantages through all the life cycle. During the planning and construction phases, more sites can be exploited, the time to market is shorter, there are less risks associated to the construction and a higher benefit for national industries. In the operation phase, SMRs provide more job positions and do not require additional costs in terms of spinning reserves.

This work represents an improvement with respect to the framework presented last year and contains its application to the Italian scenario, even if most of the considerations can apply to many countries. Further research activities include the extension of this framework to other countries interested in NPP and the integration of external factors with financial factors, in order to provide an overall evaluation of the investment. Moreover, it will be interesting to evaluate the better mix of SMRs and LRs installations. 


\section{ACRONIMS}

$\begin{array}{ll}\text { CCR } & \text { Central Control Room } \\ \text { DCF } & \text { Discounted Cash Flow } \\ \text { EPR } & \text { European Pressurized Reactor } \\ \text { FOAK } & \text { First-Of-A-Kind } \\ \text { IAEA } & \text { International Atomic Energy Agency } \\ \text { INCAS } & \text { INtegrated model for the Competitiveness Assessment of SMRs } \\ \text { LC } & \text { Largest Contingency } \\ \text { LR } & \text { Large Reactor } \\ \text { LWR } & \text { Light Water Reactor } \\ \text { MSD } & \text { Market for Dispatching Services (Italian) } \\ \text { NIMBY } & \text { Not-In-My-BackYard } \\ \text { NOAK } & \text { Nth-Of-A-Kind } \\ \text { NPP } & \text { Nuclear Power Plant } \\ \text { NPV } & \text { Net Present Value } \\ \text { NSSS } & \text { Nuclear Steam Supply System } \\ \text { OECD } & \text { Organization for Economic Co-Operation and Development } \\ \text { SMR } & \text { Small Medium Reactor } \\ \text { TSO } & \text { Transmission System Operator } \\ \text { VI } & \text { Vulnerability Index } \\ \text { WE } & \text { Worst Event }\end{array}$




\section{REFERENCES}

\section{Bibliografia}

ARIANOS, S., Bompard, E., Carbone, A. "Power grids vulnrability: a complex network approach". Chaos. 19(1).

ASSOCIATION, World Nuclear. 2008. "Structuring nuclear projects for success - An analytic framework". London, United Kingdom.

ASSOCIATION, Nuclear Industry. 2008. "The UK capabilities to deliver a new nuclear build programme - Main report". London, United Kingdom.

ASSOCIATION, World Nuclear. 2009. "Heavy manufacturing of power plants". London, United Kingdom.

BERIZZI, A., Bovo, C., Benini, M., Migliavacca, G. 2005. "I servizi ancillari e la remunerazione del reattivo nei mercati elettrici liberalizzati". Milano: Fondazione Politecnico di Milano (Italian Language).

BEZDEK, R.H., Wendling, R.M. 2006. "The impacts of nuclear facilities on property values and other factors in the sorrounding communities". International Journal of Nuclear Governance, Economy and Ecology. 1(1).

BOARIN, S., Ricotti, M.E. 2009. "Cost and profitability analysis of modular SMRs in different deployment scenarios", Paper 75741. In: Proceedings of the 17th International Conference on Nuclear Engineering ICONE 17 July 12-16. Brussels, Belgium.

CARELLI, M.D. 2003. "IRIS: final technical progress report". Windsor, United States.

CARELLI, M.D., Conway, L.E., Oriani, L., Petrovic, B., Lombardi, C.V., Ricotti, M.E., Barroso, A.C.O., Collado, J.M., Cinotti, L., Todreas, N.E., Grgic, D., Moraes, M.M., Boroughs, R.D., Ninotaka, H., Ingersoll, D.T., Oriolo, F. 2004. "The design and safety features of the IRIS reactor". Nuclear Engineering and Design. 230, pp.151-167.

CARELli, M.D., Garrone, P., Locatelli, G., Mancini, M., Mycoff, M., Trucco, P., Ricotti, M.E. 2009. "Economic features of integral, modular, small-to-medium size reactors". Progress in Nuclear Energy.

CHARLTON, W.S., Le Bouf, R.F., Gariazzo, C., Ford, D.G., Beard, C., Landsberger, S., Whitaker, M. 2008. "Proliferation resistence assessment methodology for nuclear fuel cycle". Texas, United States.

COMMISSION, U.S. Nuclear Regulatory. 2000. "Reactor Oversight Process", NUREG-1649. Washington D.C., United States.

CORBELLINI, F. November 26, 2008. Interview on "Assoedilizia Informa".

CRUCITTI, P., Latora, V., Marchiori, M. 2004. "A topological analysis of the Italian electric grid". Physica A. 338, pp.92-97.

DEMOS. 2008. "Gli italiani e l'energia nucleare". Vicenza, Italy (Italian language).

DOMINION ENERGY INC., Bechtel Power Corporation, TLG Inc., MPR Associates. 2004. "Study of construction technologies and schedules, O\&M, staffing and cost, decommissioning costs and funding requirements for advanced reactors designs". Washington D.C., United States. ECONOMICS, Oxford. 2008. "Economic, employment and environmental benefits of renewed U.S. investment in nuclear energy - National and State analysis". Wayne, United States.

ELETTRICO, Gestore del Mercato. 2007. "Relazione Annuale 2006". Rome, Italy (Italian language). 
ENERGY, U.S. Department of. 2001. "A roadmap to deploy new nuclear power plants in the United States by 2010". Washington D.C., United States.

ENERGY, U.S. Department of. 2005. "DOE NP2010 - Nuclear power plant construction infrastructure assessment". Washington D.C., United States.

FISCHOFF, B., Slovic, P., Lichtenstein, S., Read, S., Combs, B. 1978. "How safe is safe enough? A psychometric study of attitudes towards technological risks and benefits". In: Policy Sciences, Kluwer Academic Publisher, pp.127-152.

FORUM, U.S. DOE Nuclear Energy Research Advisory Committee and Generation IV Interational. 2002. "A technology roadmap for Generation IV nuclear energy systems".

FOUNDATION, EnergyLab. 2008. "Rapporto preliminare sulle condizioni per il ritorno all'energia elettronucleare in Italia". Milan, Italy (Italian language).

GALIANA, F.D., Bouffard, F., Arroyo, J.M., Restrepo, J.F. 2005. "Scheduling and pricing of coupled energy and primary, secondary and tertiary reserves". In: Proceedings of the IEEE.

GAS, Autorità per l'energia elettrica ed il. 2005. "Indagine conoscitiva sullo stato della liberalizzazione del settore dell'energia elettrica". Milan, Italy (Italian language).

GAS, Autorità per l'energia elettrica ed il. 2009. "Indagine conoscitiva sulle determinanti della dinamica del sistema dei prezzi e delle tariffe, sull'attività dei pubblici poteri e sulle ricadute sui cittadini consumatori". Milan, Italy (Italian language).

GENESI, C., Granelli, G., Marannino, P., Montagna, M., Zanellini, F., Innorta, M. July 2007. "Identification of critical outages leading to cascading failures in electrical power systems". In: IEEE Power Tech. Lausanne.

GOOI, H.B., Mendes, D.P., Bell, K.R.W., Kirschen, D.S. 1999. "Optimal scheduling of spinning reserve". IEEE Transaction on Power Systems. 14(4).

HSE, STUK, HSN. 2009. "Joint regulatory position statement on the EPR Pressurized Water Reactor", Release no. V4 22/10/2009.

IAEA. 2001. "Staffing requirements for future small and medium reactors (SMRs) based on operating experience and projections", IAEA-TECDOC-1193. Vienna, Austria.

IAEA. 2006. "Status of innovative small and medium reactor designs 2006. Reactors with conventional refueling schemes", IAEA-TECDOC-1485. Vienna, Austria: IAEA.

IAEA. 2008. "Revising the need for relocation and evacuation measures unique for NPPs for innovative SMRs" CRP IAEA 13901/13905.

INGERSOLL, D.T. 2009. "Deliberately small reactors and second nuclear era". Progress in Nuclear Energy. 51, pp.589-603.

INSTITUTE, Nuclear Energy. 2004. "Economic benefits of Diablo Canyon Power Plant", "Economic benefits of Indian Point Energy Center", "Economic benefits of Duke-Power Operated Nuclear Power Plants", "Economic benefits of Palo Verde Nuclear Generation Station". Washington D.C., Unites States.

INSTITUTE, Nuclear Energy. 2006. "Economic benefits of Salem and Hope Creek Nuclear Generating Stations", "Economic benefits of Grand Gulf Nuclear Station", "Economic benefits of PPL Sussquehanna Nuclear Power Plant". Washington D.C., United States.

KENLEY, C.R., Klinger, R.D., Plowman, C.M., Soto, R., Turk, R.J., Baker, R.L., Close, S.A., McDonnel, V.L., Paul, S.W., Rabideau, L.R. 2009. "Job creation due to nuclear power resurgence in the United States". Energy Policy. 37, pp.4894-4900.

KIRBY, B.J. 2003. "Spinning reserve from responsive loads", ORNL/TM-2003/19. Oak Ridge, Tennessee, USA: Oak Ridge National Laboratory. 
KUHNREUTHER, H., Linnerooth-Bayer, J., Fitzgerald, K. 1996. "Siting hazardous facilities: lessons from Europe and America". In: Energy, Environment and the Economy: Asian Perspectives, United Kingdom: Edward Elgar Publishing.

LABORATORY, Idaho National Engineering and Environmental. 2004. "U.S. Job creation due to nuclear power resurgence in the United States - Volume 1 and 2", INEEL/EXT-04-02384. Idaho Falls, Idaho, United States.

LOZZA, E., Mazzoletti, G. 2008. "Energia nuclare: riparliamone". Social Trends. 105, pp.14-17. MACINTOSH, A. 2007. "Siting nuclear power plants in Australia - Where would they go?".

MAIOLI, A., Finnicum, D.J., Kumagai, Y. 2004. "IRIS simplified LERF model". In: ANES 2004 Proceedings of International Conference October 2004. Miami, Florida, United States.

MANCINI, M., Locatelli, G., Tammaro, S. 2009. "Impact of the external factors in the nuclear field: a comparison between small medium reactors vs. large reactors", Paper 75689. In: Proceedings of the 17th International Conference on Nuclear Engineering ICONE 17 July 1216. Brussels, Belgium.

MATZIE, R.A. 2008. "AP1000 will meet the challenges of near-term deployment". Nuclear Engineering and Design. 238(8), pp.1856-1862.

MOYA, O.E. 2005. "A spinning reserve, load shedding and economic dispatch solution by Bender's decomposition". IEEE Transaction on Power Systems. 20(1).

O'CONNOR, P., O'Dea, A., Flin, R., Belton, S. 2008. "Identifying the team skills required by nuclear power plant operations personnel". International Journal of Industrial Ergonomics. 38, pp.1028-1037.

OECD/NEA. 2000. "Nuclear education and training - Cause for concern? Issy-les-Moulineaux, France.

OECD/NEA. 2004. "Nuclear competence building". Issy-les-Moulineaux, France.

OPERATORS, World Association of Nuclear. 2009. "2008 WANO Performance Indicators". London, United Kingdom.

ORTEGA-VASQUEZ, M.A., Kirschen, D.S., Pudijianto, D. 2006. "Optimising the scheduling of spinning reserve considering the cost of interruption". In: IEE Proceedings Generation, Transmission and Distribution.

O'SULLIVAN, J.W., O'Malley, M.J. 1999. "A new methodology for the provision of reserve in an isolated power system". IEEE Transaction on Power Systems. 14(2).

PROSPERETTI, L. 2008. Interview on "Mont Blanc Cultural Forum".

REBOURS, Y., Kirschen, D. 2005. "A survey of definitions and specifications of reserve services". Manchester, United Kingdom: The University of Manchester.

REBOURS, Y., Kirschen, D. 2005. "What is spinning reserve?" Manchester, United Kingdom: The University of Manchester.

RUIZ, P.A., Sauer, P.W. 2008. "Spinning contingency reserve: economic value and demand function". IEEE Transaction on Power System. 23(3).

SCHNEIDER, M., Thomas, S., Froggatt, A., Koplow, D. 2009. "The world nuclear industry report 2009 - With particular emphasis on economic issues". Paris.

SFORNA, M., Delfanti, M. 2006. "Overview of the events and causes of the 2003 Italian blackout". In: IEEE PES Power Systems Conference and Exposition., pp.301-308.

SJOBERG, L. 1999. Risk perception by the public and by experts: a dilemma in risk management". Human Ecology Review. 6, pp.1-9.

SJOBERG, L. 2009. "Public risk perception of nuclear waste". International Journal of Risk Assessment and Management. 11(3), pp.264-296. 
SLOVIC, P., Fischoff, B., Lichtenstein, S. 1980. "Facts and fears: understanding perceived risks". In: Societal risk assessment: how safe is safe enough, New York: Plenum.

SLOVIC, P. 1993. "Perceived risk, trust and democracy". Risk analysis. 13(6), pp.675-682.

SOCIETÀ, ARIS Agenzia di Ricerche Informazione e. 2008. "A passo lento. Energia, ambiente e infrastrutture in Italia". Milan, Italy (Italian language).

STREIFFERT, D. 1995. "Multi-area economic dispatch with tie line constraints". IEEE Transaction on Power Systems. 10(4).

TANAKA, Y. 2004. "Major psychological factors determining public acceptance of the siting of nuclear facilities". Journal of Applied Social Psycology. 34(8), pp.1147-1165.

TERNA. 2004. "Codice di trasmissione, dispacciamento, sviluppo e sicurezza della rete". Rome, Italy (Italian language).

TERNA. 2008. "Dati provvisori di esercizio del sistema elettrico nazionale". Rome, Italy (Italian language).

TERNA. 2009. "Piano di sviluppo 2009". Rome, Italy (Italian language).

WALLACE, E., Matzie, R., Heiderd, R., Maddalena, J. 2006. "From field to factory - Taking the advantage of shop manufacturing for the Pebble Bed Modular Reactor". Nuclear Engineering and Design. 236, pp.445 - 453. 